\title{
Comparison of Electroporation Threshold for Different Cell Lines in vitro
}

\author{
G. SAUlis* AND R. SAulĖ \\ Vytautas Magnus University, 58 K. Donelaičio str., Kaunas, Lithuania
}

\begin{abstract}
The electroporation threshold was compared at various electric pulse durations for three cell lines: two non-tumor cell lines (human erythrocytes and Chinese hamster ovary cells) and one tumor cell line (rat glioma C6 cells). First, the dependences of the fraction of electroporated cells on the pulse intensity were obtained for the cells exposed to single square-wave electric pulses with the durations of $0.02-2 \mathrm{~ms}$. Then, the average cell radii were measured for each cell line and the transmembrane potential induced by the external electric field was calculated. The obtained values of the transmembrane potential were in the range of $480-930 \mathrm{mV}$ and decreased with increasing pulse duration. The obtained dependences of the transmembrane potential required to electroporate $50 \%$ of cells on the pulse duration were close to each other for all cell lines studied.
\end{abstract}

PACS numbers: 87.50.cj, 87.80.Fe, 87.50.cf

\section{Introduction}

The permeability of the cell membrane can be modified by exposure of cells to high-voltage electric pulses, which leads to the creation of pores in the cell membrane (electroporation) [1]. When using cell electroporation in clinics, e.g., for tumor and gene therapy, it is important to know in advance whether and how many of cells will become electroporated as a result of a particular electric treatment. This could be achieved by using theoretical models of electroporation [2], optimized by using real experimental data on cell electroporation $[3,4]$.

There are theoretical models allowing to obtain theoretical relationships between the parameters of the electric treatment resulting in cell electroporation for any type of an electric treatment $[4,5]$. However it is difficult to predict individual responses of different cells to electric treatment $[6,7]$, because there are no studies in which the electroporation threshold would be compared for different cell lines. Either the electric field parameters needed for the increase of the cell membrane permeability to a particular substance (electropermeabilization) [6] or cell viability [7] have been determined for several cell lines. As a result, the fraction of electroporated cells still needs to be determined empirically for each cell line [7].

The aim of this study was to compare the electroporation threshold for three different cell lines at various electric pulse durations $(20 \mu \mathrm{s}-2 \mathrm{~ms})$ in vitro. Experiments were performed with one tumor (rat glioma C6 cells) and two non-tumor (human erythrocytes and Chinese hamster ovary cells) cell lines.

* corresponding author; e-mail: g.saulis@gmf.vdu.lt

\section{Materials and methods}

Experiments were performed with red blood cells, Chinese hamster ovary $(\mathrm{CHO})$, and rat glioma $\mathrm{C} 6$ cells. Blood was collected on sodium citrate and the erythrocytes were isolated by centrifugation. The erythrocytes were then washed three times with isotonic sodium chloride solution and suspended in the electroporation medium at a volume concentration of $2-2.5 \%$ [8]. $\mathrm{CHO}$ and rat glioma $\mathrm{C} 6$ cells were grown in monolayer cultures in $75 \mathrm{~cm}^{2}(200 \mathrm{ml})$ flasks at $37^{\circ} \mathrm{C}$ and $5 \% \mathrm{CO}_{2}$ in water-jacketed incubator IR AutoFlow NU-2500E (NuAire, Plymouth, MN, USA). When cells reached confluence they were trypsinazed for 2 to $10 \mathrm{~min}$ with $2 \mathrm{ml}$ of $0.25 \%$ trypsin- $0.02 \%$ ethylenediaminetetraacetic acid (EDTA) solution (cat. no. T4049, Sigma-Aldrich Chemie). When cells detached from the flask bottom, cell suspension was supplemented with $2 \mathrm{ml}$ culture medium. After centrifugation of the suspension for 5 min at $1000 \mathrm{rpm}$, cells were resuspended in the culture medium at approximately $2-5 \times 10^{7}$ cells $/ \mathrm{ml}$ and kept for $60-70 \mathrm{~min}$ at room temperature $\left(20-21^{\circ} \mathrm{C}\right)[9]$.

A $50 \mu \mathrm{l}$ droplet of cell suspension was placed between a pair of flat stainless-steel electrodes and subjected to a single square-wave electric pulse. The distance between the electrodes was $2 \mathrm{~mm}$. After the electric treatment, the cells were immediately transferred to a chilled Eppendorf tube, kept on ice for 5-10 min, and then kept for $30-40 \mathrm{~min}$ at $10-11^{\circ} \mathrm{C}$ to prevent pores from closing and to allow equilibration between intracellular and extracellular $\mathrm{K}^{+}$concentrations. Then, the extracellular potassium concentration was measured by means of a mini $\mathrm{K}^{+}$-selective electrode and the fraction of electroporated cells was determined $[8,9]$. 


\section{Results and discussion}

When the cell is electroporated, $\mathrm{K}^{+}$ions leak out of the cell down their concentration gradient until the equilibration between intracellular and extracellular $\mathrm{K}^{+}$concentrations occurs. So, the fraction of electroporated cells can be determined from the extracellular concentration of $\mathrm{K}^{+}$ions $[8,9]$.

In this study, the dependences of the fraction of electroporated cells on the pulse intensity were obtained for the cells exposed to a single square-wave electric pulse with the duration of $0.02-2 \mathrm{~ms}$. The amplitude of an electric pulse was varied from 0.6 to $2 \mathrm{kV} / \mathrm{cm}$ for erythrocytes and from 0.2 to $1.5 \mathrm{kV} / \mathrm{cm}$ for $\mathrm{CHO}$ and rat glioma $\mathrm{C} 6$ cells. These dependences obtained for human eryhtrocytes are shown in Fig. 1. It can be seen that increasing the intensity or the duration of the electric field pulse increased the fraction of electroporated cells (Fig. 1). The dependences of the fraction of electroporated cells on the pulse intensity were obtained for other cells, too (data not shown).

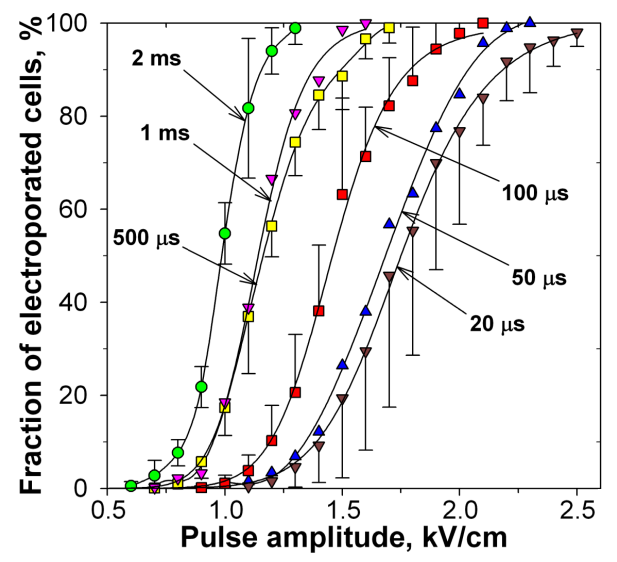

Fig. 1. Dependences of the fraction of electroporated human erythrocytes on the amplitude of an electric field pulse for various pulse durations. Cells were exposed to a square-wave pulse with a duration of $20 \mu \mathrm{s}-2 \mathrm{~ms}$ and the fraction of electroporated cells was determined from the amount of potassium ions released from the cells (see Sect. 2).

From the relationships of the fraction of electroporated cells on the pulse amplitude obtained at different pulse durations, the pulse amplitude inducing electroporation of $50 \%$ of cells, $\Delta \Phi_{m 50 \%}$, can be estimated for each pulse length. This way, the dependence of $\Delta \Phi_{m 50 \%}$ on the pulse duration can be obtained. Such dependences obtained for human erythrocytes, Chinese hamster ovary and rat glioma $\mathrm{C} 6$ cells are shown in Fig. 2A. It can be seen that electroporation of $\mathrm{CHO}$ and rat glioma $\mathrm{C} 6$ cells require the electric pulses of similar amplitude. However, to electroporate human erythrocytes the pulse of much higher amplitude has to be used.

However, the transmembrane potential generated by the external electric field depends on the cell radius [10].

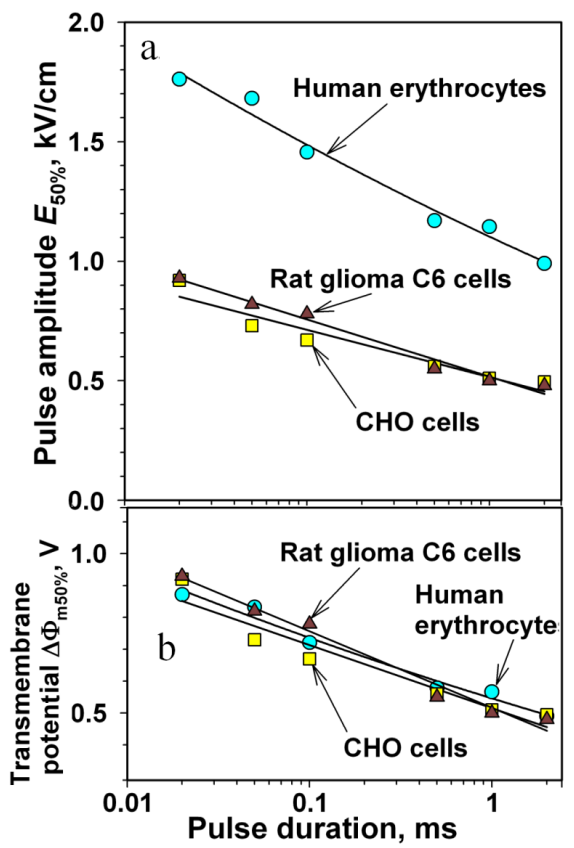

Fig. 2. The dependences of (A) the amplitude of a square-wave electric pulse and (B) the maximal transmembrane potential (at the poles of the cell) required to electroporate $50 \%$ of cells on the pulse duration, obtained for human erythrocytes, $\mathrm{CHO}$, and rat glioma C6 cells.

Meanwhile, human erythrocytes, $\mathrm{CHO}$, and rat glioma C6 cells differ in their sizes. Therefore the electric field strength necessary to electroporate the cells of different sizes cannot be compared. Only the maximal transmembrane potential (at the polar regions of the cell) induced by the external electric field can be compared. So, the transmembrane potential inducing electroporation of $50 \%$ of cells, $\Delta \Phi_{m 50 \%}$, was calculated from equation [10]

$$
\Delta \Phi_{m}=1.5 E_{0} a
$$

where $E_{0}$ is the electric field strength and $a$ is the cell radius.

The obtained dependences of $\Delta \Phi_{m 50 \%}$ on the pulse duration are presented in Fig. 2B. The average cell radius was $3.0 \mu \mathrm{m}$ for human erythrocytes, $7.0 \mu \mathrm{m}$ for Chinese hamster ovary cells, and $6.5 \mu \mathrm{m}$ for rat glioma C6 cells. From Eq. (1) we get the values of the transmembrane potential in the range of $480-930 \mathrm{mV}$ (Fig. 2B), which are similar to the transmembrane potentials that have been reported as leading to membrane permeabilization when using the pulses of similar duration $[6,11]$. It can be seen from Fig. 2A that the dependences of the transmembrane potential required to electroporate $50 \%$ of cells are very close for all cell lines studied here.

\section{Conclusions}

It can be concluded that the electric field strength necessary to electroporate cells depends on the cell size and decreases with increasing the amplitude or the duration 
of the pulse. But the transmembrane potential required to electroporate $50 \%$ of cells as well as its dependence on the pulse duration is almost the same for human erythrocytes, Chinese hamster ovary $(\mathrm{CHO})$ and rat glioma C6 cells.

\section{Acknowledgments}

This work was in part supported by grant T-69/07 from the Lithuanian Science and Studies Foundation.

\section{References}

[1] J. Gehl, Acta Physiol. Scand. 177, 437 (2003).

[2] D. Sel, D. Cukjati, D. Batiuskaite, T. Slivnik, L.M. Mir, D. Miklavcic, IEEE Trans. Biomed. Eng. 52, 816 (2005).

[3] J. Gehl, L.M. Mir, Biochem. Biophys. Res. Commun. 261, 377 (1999).

[4] G. Saulis, P.C. Wouters, in Food Preservation by Pulsed Electric Fields: From Research to Application, Eds. H.L.M. Lelieveld, S. Notermans, S.W.H. De Haan, Woodhead Publishing Limited, Cambridge 2007, p. 138.
[5] G. Saulis, M.S. Venslauskas, Bioelectrochem. Bioenerg. 32, 221 (1993).

[6] M. Cemazar, T. Jarm, D. Miklavcic, A.M. Lebar, A. Ihan, N.A. Kopitar, G. Sersa, Electro- and Magnetobiology 17, 263 (1998).

[7] M.J. O'Hare et al., in Electrochemotherapy, Electrogenetherapy, and Transdermal Drug Delivery, Eds. M.J. Jaroszeski, R. Heller, R. Gilbert, Humana Press Inc., Totowa, NJ 2000, p. 319.

[8] G. Saulis, R. Praneviciute, Anal. Biochem. 345, 340 (2005).

[9] G. Saulis, S. Satkauskas, R. Praneviciute, Anal. Biochem. 360, 273 (2007).

[10] H.P. Schwan, Adv. Biol. Med. Phys. 5, 147 (1957).

[11] B. Gabriel, J. Teissie, Biophys. J. 76, 2158 (1999). 